\title{
polo encodes a protein kinase homolog required for mitosis in Drosophila
}

\author{
S. Llamazares, A. Moreira, ${ }^{1}$ A. Tavares, ${ }^{1}$ C. Girdham, B.A. Spruce, C. Gonzalez, R.E. Karess, ${ }^{2}$ \\ D.M. Glover, ${ }^{3}$ and C.E. Sunkel ${ }^{1}$ \\ Cancer Research Campaign, Cell Cycle Genetics Group, Department of Biochemistry, The University, Dundee DD1 4HN, \\ Scotland; 'Laboratorio de Genetica Molecular, Centro de Citologia Experimental, Instituto Nacional de Investigaçâo \\ Cientifica, Universidade do Porto, 4100 Porto, Portugal; ${ }^{2}$ Department of Biochemistry, New York University Medical \\ School, New York, New York 10016 USA
}

\begin{abstract}
We show that mutation in polo leads to a variety of abnormal mitoses in Drosophila larval neuroblasts. These include otherwise normal looking mitotic spindles upon which chromosomes appear overcondensed; normal bipolar spindles with polyploid complements of chromosomes; bipolar spindles in which one pole can be unusually broad; and monopolar spindles. We have cloned the polo gene from a mutant allele carrying a P-element transposon and sequenced cDNAs corresponding to transcripts of the wild-type locus. The sequence shows that polo encodes a 577-amino-acid protein with an amino-terminal domain homologous to a serine-threonine protein kinase. polo transcripts are abundant in tissues and developmental stages in which there is extensive mitotic activity. The transcripts show no obvious spatial pattern of distribution in relation to the mitotic domains of cellularized embryos but are specifically concentrated in dividing cells in larval discs and brains. In the cell cycles of both syncytial and cellularized embryos, the polo kinase undergoes cell cycle-dependent changes in its distribution: It is predominantly cytoplasmic during interphase; it becomes associated with condensed chromosomes toward the end of prophase; and it remains associated with chromosomes until telophase, whereupon it becomes cytoplasmic.
\end{abstract}

[Key Words: Mitosis; Drosophila; protein kinase; polo]

Received August 19, 1991; accepted September 12, 1991.

Genes essential for mitosis in Drosophila have been identified by mutations that arrest development at stages in which this process is crucial. One such stage is the syncytial embryo in which there are 13 rounds of mitosis in the first $2 \mathrm{hr}$ of development (Zalokar and Erk 1976; Foe and Alberts 1983). These cycles are dependent on maternally provided gene products (Szabad and Bryant 1982). Some of these maternally expressed genes, for example gnu (Freeman et al. 1986), $a b c$ (Underwood et al. 1990; Vessey et al. 1991), and $f_{S}(1) \mathrm{Ya}$ (Lin and Wolfner 1991), encode products that appear to be specifically required for the syncytial divisions. Females homozygous for the gnu mutation produce eggs that undergo many rounds of DNA synthesis in the absence of mitosis, to give giant nuclei (Freeman and Glover 1987). $f s(1) Y a$ is required for the first and subsequent embryonic mitoses and encodes a cell cycle-dependent nuclear envelope component (Lin and Wolfner 1991). Other maternally active genes encode products that persist only for the syncytial stages and are replaced by the zygotic product following cellularization during the fourteenth cycle. This cycle no longer takes place synchronously throughout the embryo but, instead, cells divide within a series of

${ }^{3}$ Corresponding author. mitotic domains (Foe 1989). string (Edgar and O'Farrell $1989 ; 1990$ ) exemplifies a gene whose products have to be synthesized de novo at this time, following the degradation of its maternally encoded gene products. Thus, embryos homozygous for mutations in these genes can undertake all of the syncytial mitoses utilizing wild-type protein provided by the heterozygous mother, and cell cycle progression is only prevented following cellularization. The string gene encodes a protein homologous to the cell cycle control gene $c d c 25$ of fission yeast (Edgar and O'Farrell 1989, 1990; Jimenez et al. 1990), which activates $c d c 2$. $c d c 2$ encodes the catalytic subunit of a protein kinase essential for the $G_{2}-M$ transition in diverse organisms (for review, see Nurse 1990). Thus, the controlled expression of string is thought to regulate the length of the $G_{2}$ phase within the mitotic domains of newly cellularized Drosophila embryos (Edgar and O'Farrell 1990|. Mutations in the final category of genes can arrest development either in the embryo or at late larval stages of development in an allele-specific manner. In these cases, maternally provided wild-type proteins appear to persist until the larval stages of development, in which most cells undergo growth and polyploidization rather than proliferating. Thus, aberrant mitosis is first seen in proliferating cells of imaginal 
discs and the central nervous system in late larval development. This general phenotype was first recognized by observations of Gatti and co-workers (Gatti et al. 1983; Gatti and Baker 1989) on mutations resulting in late larval or early pupal lethality. polo is such a gene in which animals homozygous for a strong mutant allele, polo ${ }^{2}$, die as larvae (Sunkel and Glover 1988). The original weaker polo ${ }^{1}$ allele was, however, first detected by its female sterile phenotype. Many females homozygous for this mutation do survive to adulthood but then produce embryos that are unable to undertake the syncytial mitotic cycles. Thus, the polo gene product is likely to be required at all proliferative stages of Drosophila development.

We showed previously that females homozygous for polo ${ }^{1}$ produce embryos that have complex networks of chromatin associated with branched and highly irregular arrays of microtubules (Sunkel and Glover 1988). It is not possible to visualize centrosomes in these embryos by using antibodies against the centrosomal-associated antigen Bx63 (Frasch et al. 1985; Whitfield et al. 1988). Orcein-stained preparations of larval neuroblasts showed a large number of polyploid cells, some of which appeared to have circular arrangements of condensed chromosomes. We were also able to detect abnormal chromosome disjunction in male meiosis, both by direct microscopical examination of living cells and by following the disjunction of marked chromosomes. In this paper we evaluate the mitotic phenotype shown in larval neuroblasts by applying recently developed immunostaining techniques. We show that the polo gene product encodes a putative serine-threonine protein kinase that undergoes cyclical changes in its distribution during embryonic mitoses.

\section{Results}

The effect of polo ${ }^{1}$ on mitotic spindles

Previously, we have described the effects of the polo ${ }^{1}$ mutation upon mitotic chromosomes in aceto-orceinstained preparations of squashed third-instar larval brains. We were concerned that these techniques destroy the mitotic spindles and distort the three-dimensional arrangement of chromosomes within these cells and so chose to re-examine the larval neuroblast phenotype by using recently developed techniques for indirect immunofluorescence with confocal microscopy (Axton et al. 1990; Gonzalez et al. 1990; C. Gonzalez and D.M. Glover, in prep.). We find a wide range of spindle morphologies within these cells (Fig. 1), which include those with a normal complement of chromosomes aligned on the metaphase plate of spindles that appear wild type, such as the example shown in Figure 1A. The mitotic figure in Figure 1B, on the other hand, is unusual in that although the extent of chromosome condensation is more like that normally seen at metaphase, the distribution of chromosomes is typical of prophase, the chromosomes not being aligned on a metaphase plate. Chromosome condensation can be even more extreme, as though this process is continuing to occur even though other aspects of mitosis are delayed. This is evident in the anaphase figure shown in Figure 1C. In this case, the chromosomes show a similar state of overcondensation to those reported previously in orcein-stained preparations (Sunkel and Glover 1988). The field shown at lower magnification in Figure 1D has five mitotic cells with condensed chromosomes, four of which are clearly at metaphase and have their chromosomes associated with bipolar spindles. Closer examination of such spindles often reveals abnormalities: the metaphase figures in Figure $1 \mathrm{E}$ are both polyploid, but whereas the spindle of the upper cell has a wild-type appearance, the spindle of the lower cell has one unusually broad pole. Finally, a proportion of the mitotic figures are monopolar structures in which chromosomes are arranged in a circle around a large aster of microtubules. When immunostained to reveal the Bx63 antigen (Frasch et al. 1985; Whitfield et al. 1989; not shown), such structures are seen to be nucleated from a central single centrosome.

\section{Molecular localization of polo}

To clone polo we have used a mutant allele tagged with the P-element transposon. This was identified within a collection of larval lethal mutations on the third chromosome induced by the mobilization of multiple P elements by P-M hybrid dysgenesis (R.E. Karess and D.M. Glover, unpubl.). As the third chromosome of the K3.1 stock carrying polo $^{2}$ carried five additional P elements, it was necessary to perform three successive recombination experiments both to eliminate unwanted $P$ elements and identify the element responsible for the mutation (for details, see Materials and methods). In all stocks carrying either recombinant or revertant chromosomes, we found that the polo phenotype correlated with the presence of a P element at $77 \mathrm{~A} 3$. The location of this $P$ element is in good agreement with that expected of the polo locus from its mapping by meiotic recombination (3-46.8 \pm 0.1$)$. Recombinant chromosome 3 appeared to contain only a single P element at $77 \mathrm{~A} 3$ by in situ hybridization. We therefore constructed a genomic library of DNA from flies in which the recombinant chromosome 3 was balanced over TM3. Screening of this library with a $\mathrm{P}$ element probe identified two classes of recombinant phage that hybridized to wild-type polytene chromosomes at sites $77 \mathrm{~A} 3$ and $82 \mathrm{C}$. We believe that the second insertion at $82 \mathrm{C}$ is a defective $\mathrm{P}$ element detected more easily by filter hybridization to a phage library than by hybridization to polytene chromosomes. DNA fragments from the class of recombinant phage shown to originate from $77 \mathrm{~A}$ were then used to screen a genomic library from the Canton-S wild-type strain. We isolated three such phage that correspond to overlapping DNA fragments from a 22 -kb region of wild-type third chromosome DNA from 77A3 (Fig. 2). A comparison of the restriction endonuclease cleavage map of the $\lambda$ phage carrying DNA from this region of the recombinant chromosome 3, E7P (Fig. 2), suggests that the polo ${ }^{2}$ mutation 
Figure 1. Mitotic figures in polo neuroblasts. Whole-mount preparations of third larval instar polo brains were prepared for immunostaining as described previously (Gonzalez et al. 1990). The preparations were stained to reveal DNA with propidium iodide, and microtubules, using as primary antibody the rat monoclonal YL1/2, were detected with fluorescein-conjugated goat anti-rat antibody (Jackson Immunochemicals). The confocal images in $A, B$, and $C$ show a wild-type-like metaphase, an abnormal prophase, and an anaphase figure with overcondensed chromosomes, respectively. These three fields are at comparable magnification such that the bar length would correspond to $4 \mu \mathrm{m}$. $D$ shows a larger field at about one-third of this magnification showing a high mitotic index. $E$ shows two spindles, the lower of which has one normal pole and one broad pole. Bar, $6 \mu \mathrm{m}$. The field in $F$ has a monopolar structure.
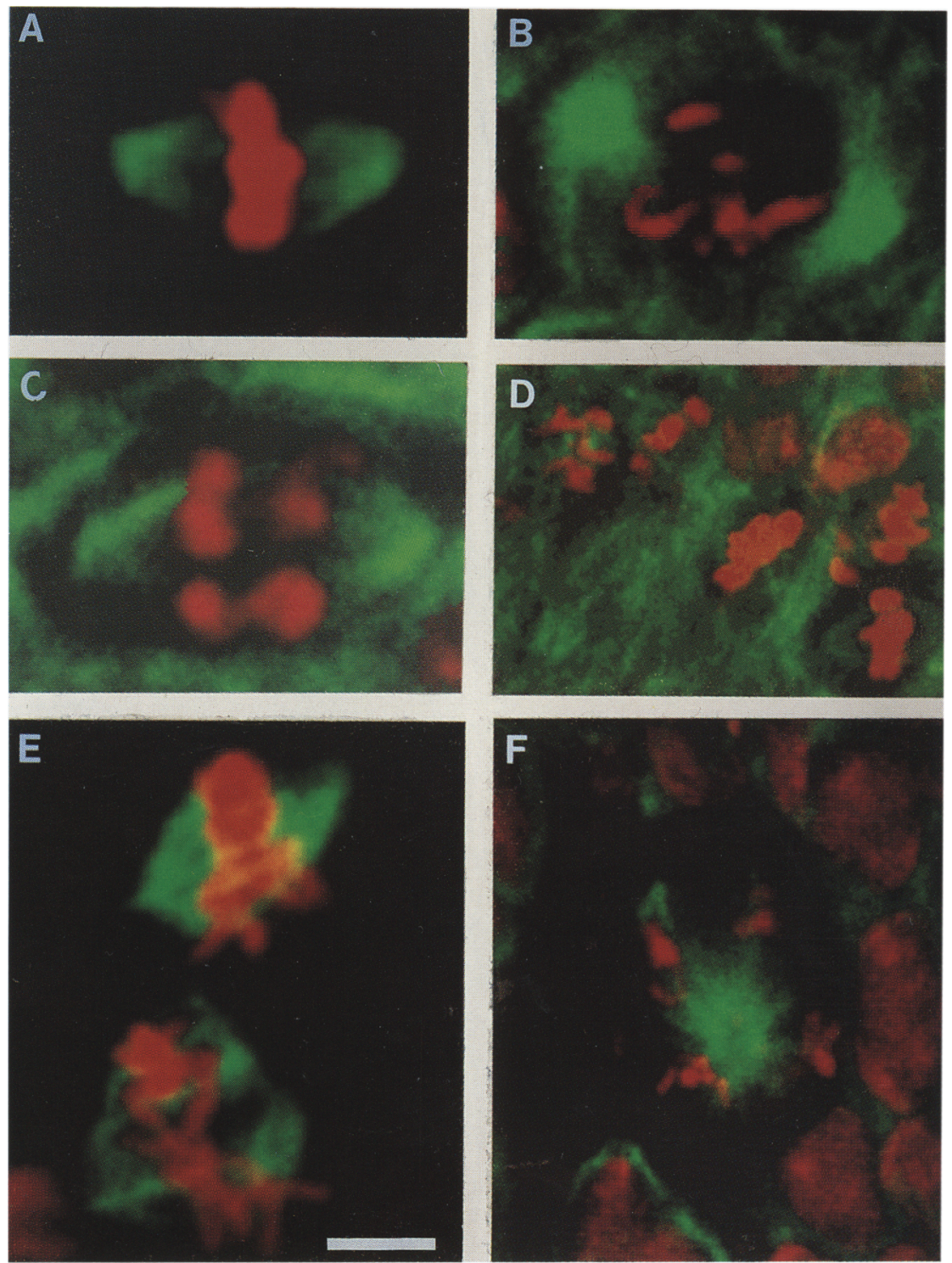

results from the insertion of a defective $1.6-\mathrm{kb} \mathrm{P}$ element.

To show that the cloned sequences at the site of the $\mathrm{P}$ element at $77 \mathrm{~A}$ were able to provide the wild-type polo function, we reintroduced this DNA into flies by P-element-mediated germ-line transformation (Materials and methods). We subcloned a $10-\mathrm{kb}$ BamHI fragment from the recombinant phage $\lambda E l$ (Fig. 2) into a P-element transformation vector. We established five lines of transformed flies and found that chromosomes carrying the transposon with DNA from 77A3 were able to rescue both the female sterility of polo $^{1}$ and the lethality of polo ${ }^{2}$ (Materials and methods), indicating that the polo gene is contained within this DNA segment.

polo transcripts are abundant during stages of development at which there is extensive mitosis

To assess whether the developmental pattern of polo ex- pression corresponded with that expected of a gene required for mitosis, we first carried out a Northern blot using the insert from the phage $\lambda E 1$ that contains the polo gene (Fig. 2) to probe RNA from the major stages of Drosophila development. Figure 3I shows that this DNA fragment detects two transcripts of 2.2 and $2.5 \mathrm{~kb}$, whose temporal pattern of expression is indistiguishable. The transcripts are present throughout development, being particularly abundant in adult females and early embryos. This pattern of expression reflects the requirement for the synthesis of cell-cycle proteins during oogenesis, embryogenesis, and late larval and early pupal stages and has been observed previously for the Drosophila cell-cycle genes cyclins A and B (Lehner and O'Farrell 1989, 1990a; Whitfield et al. 1989, 1990), cdc2 (Jimenez et al. 1990; Lehner and O'Farrell 1990b), and string (Edgar and $O^{\prime}$ Farrell 1989, 1990; Jimenez et al. 1990).

Localization of the polo transcripts by in situ hybrid- 


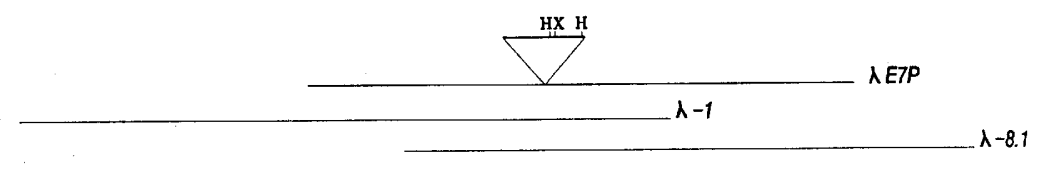

Figure 2. Molecular map of the polo locus at 77A. Top The relative positions of four recombinant bacteriophage containing DNA from $77 \mathrm{~A}$, with respect to the genomic map shown below them. The scale on this map is given in kilobases with respect to the site of the P-element insertion in the polo mutant DNA carried in phage $\lambda E 7 P$. The three other phage carry wild-type DNA. Transcripts have been positioned with respect to the genomic map by comparison of the cDNA clone sequences (Fig. 4) with the genomic sequence (A. Moreira, A. Tavares, and C.E. Sunkel, unpubl.). The indicated fragments of the cDNA clone $\mathrm{p} 9 \mathrm{a} 2$ were inserted into expression vectors as described in the Materials and methods.

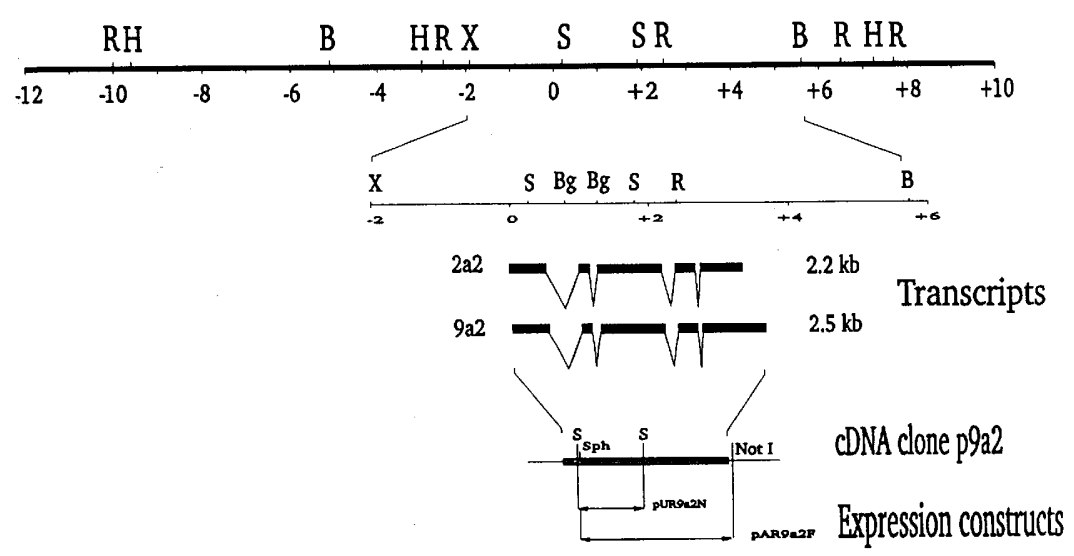

ization shows that the embryonic transcripts are initially present throughout the syncytial embryo and come to occupy a cortical layer during blastoderm in a manner that resembles the distribution of cyclin A RNA (Whitfield et al. 1989; Raff et al. 1990) (Fig. 3II, A,B,D). Following cellularization, the distribution of polo RNA corresponds only broadly to those regions of the embryo undergoing division (Fig. 3II, C), and we do not see specific association of the transcripts with mitotic domains as is seen with the string gene (Edgar and O'Farrell 1989). polo transcripts are also abundant in larval tissues that contain diploid cells (Fig. 3III), such as the testis (A,B), $\operatorname{discs}(C, D)$, and brain $(E, F)$. In these tissues, the RNA is most abundant within cell types undergoing proliferation. Thus, the strongest signals in the brain can be seen within the proliferating centers of the optic lobes $(0)$ and within that part of the ventral ganglion $(v)$ that gives rise to thoracic innervation. This region of the ventral ganglion has been shown to have greater numbers of dividing neuroblasts (Truman and Bate 1988).

\section{polo encodes a protein kinase homolog}

We have isolated and sequenced two cDNA clones, p2a2 and $\mathrm{p} 9 \mathrm{a} 2$, which correspond to the 2.2- and $2.5-\mathrm{kb}$ transcripts, respectively. Each of these contains an identical open reading frame encoding a 577-amino acid protein (Fig. 4). The longer cDNA differs from the shorter by additional nucleotides in both the $5^{\prime}$ and $3^{\prime}$ regions. The protein comprises two domains. The amino-terminal 277 amino acids show considerable identity with the catalytic domains of protein kinases. Hanks et al. (1988) have devised a phylogenetic tree of protein kinases based on the extent of sequence identity within 11 conserved regions within their catalytic domains. We have carried out a computer data base search that shows the polo kinase to be related most closely to a cluster of kinases that they identify encoded by the budding yeast genes
SNFl, KIN1, and KIN2 and the fission yeast gene nim1, and is thus likely to phosphorylate serine and threonine residues (see discussion by Hanks et al. 1988). Within subdomain VIII of polo we find the sequence Gly-ThrAla-Asn-Tyr-Ile-Ala-Pro-Glu, which conforms to the consensus sequence described by Hanks et al. (1988) as typical of Ser-Thr protein kinases. The polo kinase is next most closely related to the cyclic nucleotide-dependent kinases. The sequence relationships between such kinases and protein kinases known to be essential for entry into mitosis are shown in Figure 5.

The polo kinase shows cyclical changes in its distribution during embryonic mitoses

To facilitate the characterization of the polo gene product in Drosophila cells, we have raised antibodies against the protein expressed in bacteria (see Materials and methods). To confirm that cDNAs representative of the two classes of transcripts encode the same protein as indicated from their DNA sequence and to determine the size of this protein, we took advantage of the directional cDNA cloning procedure that positions the cDNAs downstream of an SP6 promoter (Brown and Kafatos 1988). We transcribed the two cDNAs in vitro using SP6 polymerase, translated the product using a reticulocyte lysate, and subjected it to immunoprecipitation using rabbit antisera that had been preabsorbed against $\beta$-galactosidase. A $65-\mathrm{kD}$ polypeptide was precipitated from the in vitro transcription/translation product of both cloned cDNAs (Fig. 6A). Antibodies against the bacterially expressed polo protein also specifically recognize a single polypeptide of $65 \mathrm{kD}$ in extracts of Drosophila embryos subjected to immunoblotting (Fig. 6B).

We have used both polyclonal and monoclonal antibodies to follow the distribution of the polo protein throughout mitosis in syncytial blastoderm embryos by 

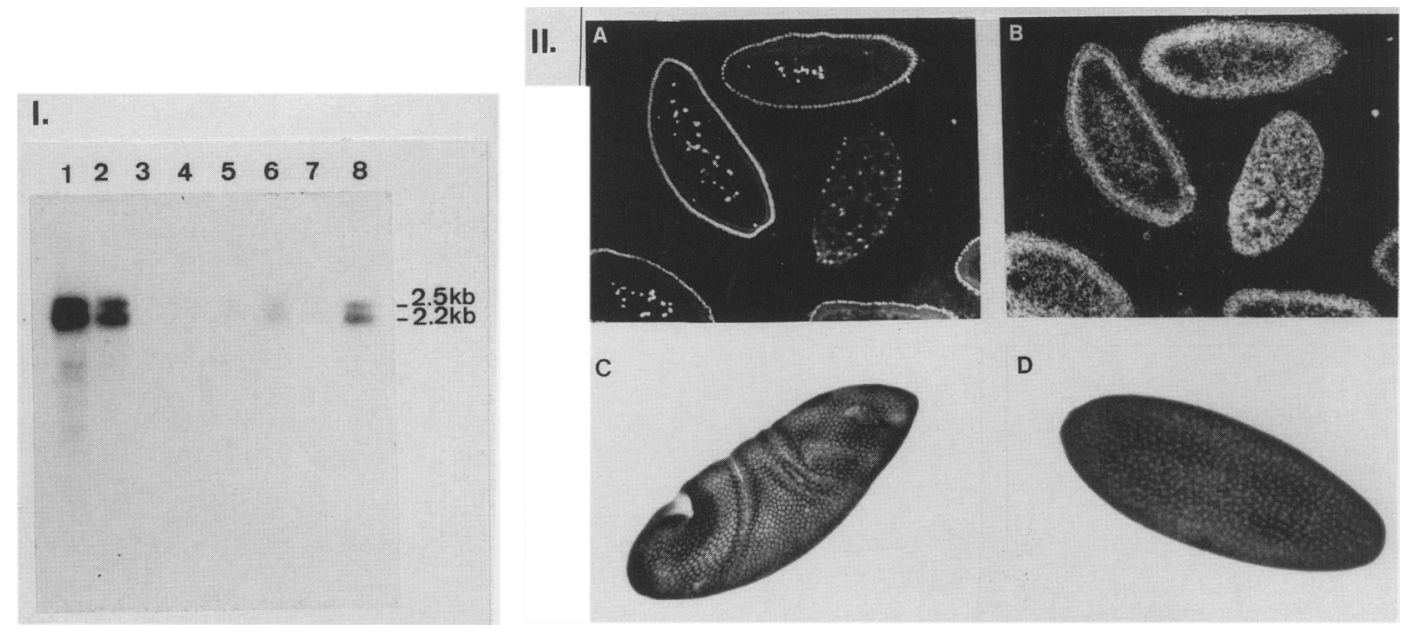

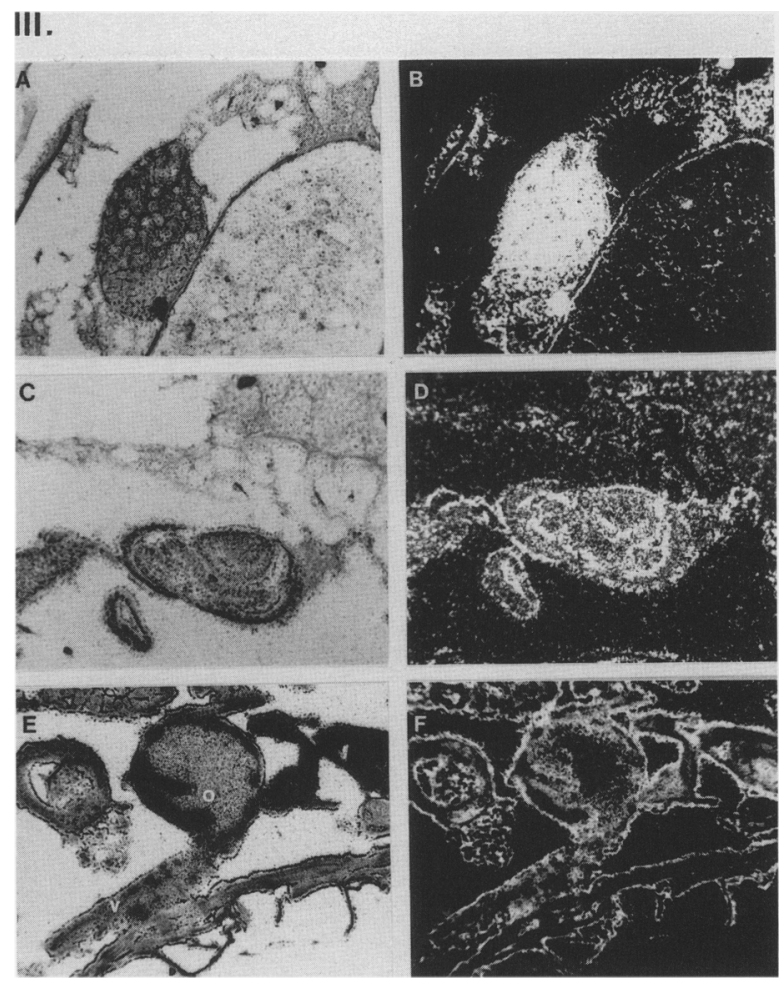

indirect immunofluorescence. Different antibodies give equivalent staining patterns, examples of which are shown in Figure 7 illustrating the different stages of mitosis during the syncytial division cycle 13 . During interphase, the polo protein is located predominantly in the cytoplasm (A). This cytoplasmic immunostaining becomes less pronounced during prophase $(B)$, as the antigen begins to associate with condensing chromatin. Chromatin association is strongest at metaphase and anaphase $(\mathrm{C}, \mathrm{D})$, and during telophase the antigen appears to dissociate from chromosomes and cytoplasmic staining returns. This cyclical behavior is also seen in the newly cellularized embryo (Fig. 8). Figure 8 shows the anterior pole of an embryo that exhibits several of the
Figure 3. Developmental regulation of polo transcripts. (I) Northern blots. RNA from the following developmental stages was prepared for blotting as described in Whitfield et al. (1989): (Lane 1) 0- to 4-hr embryos; (lane 2) 4- to 22-hr embryos; (lane 3) first-instar larvae; (lane 4) second-instar larvae; (lane 5) third-instar larvae; (lane 6) pupae; (lane 7) adult males; (lane 8) adult females. (II) Localization of transcripts in embryos. $(A, B)$ Sections of embryos at various stages of syncytial development prepared for in situ hybridization with ${ }^{35} \mathrm{~S}$ labeled probes as described in Raff et al. (1990). Nuclei revealed by Hoechst fluorescence can be seen in $A$, silver grains deposited in the emulsion following the development of the autoradiogram are shown in dark-field optics in $B .(C, D)$ A cellularized cycle 14 embryo and a syncytial embryo, respectively, following the in situ hybridization of whole-mount preparations using the digoxygenin-labeling technique developed by Tautz and Pfeifle (1989). (III) Localization of transcripts in proliferating larval tissues. In situ hybridizations carried out on sections of third-instar larvae with ${ }^{35} \mathrm{~S}$-labeled probes. Bright-field micrographs are shown at left $(A, C, E)$, with the corresponding dark field images at right $(B, D, F)$. The sections illustrate polo expression in testis $(A, B)$, an imaginal disc $(C, D)$, and brain $(E, F)$. The signal in the brain is particularly strong in the proliferating centers of the optic lobes $(\mathrm{o})$ and within the thoracic segments of the ventral ganglion $(\mathrm{v})$. cycle 14 mitotic domains. The strongest staining is seen in interphase cells (i) in which the antigen is cytoplasmic. The staining becomes spread throughout cells as they progress through prophase (p), coming to associate with the condensed chromosomes during metaphase and anaphase $(\mathrm{m} / \mathrm{a})$.

\section{Discussion}

The sequence of the polo protein shows it to have at least two domains: the amino-terminal, which is most closely related to the catalytic domain of a family of serine/ threonine protein kinases represented by the budding yeast genes SNF1, KIN1, and KIN2, and the fission yeast 
Llamazares et al.

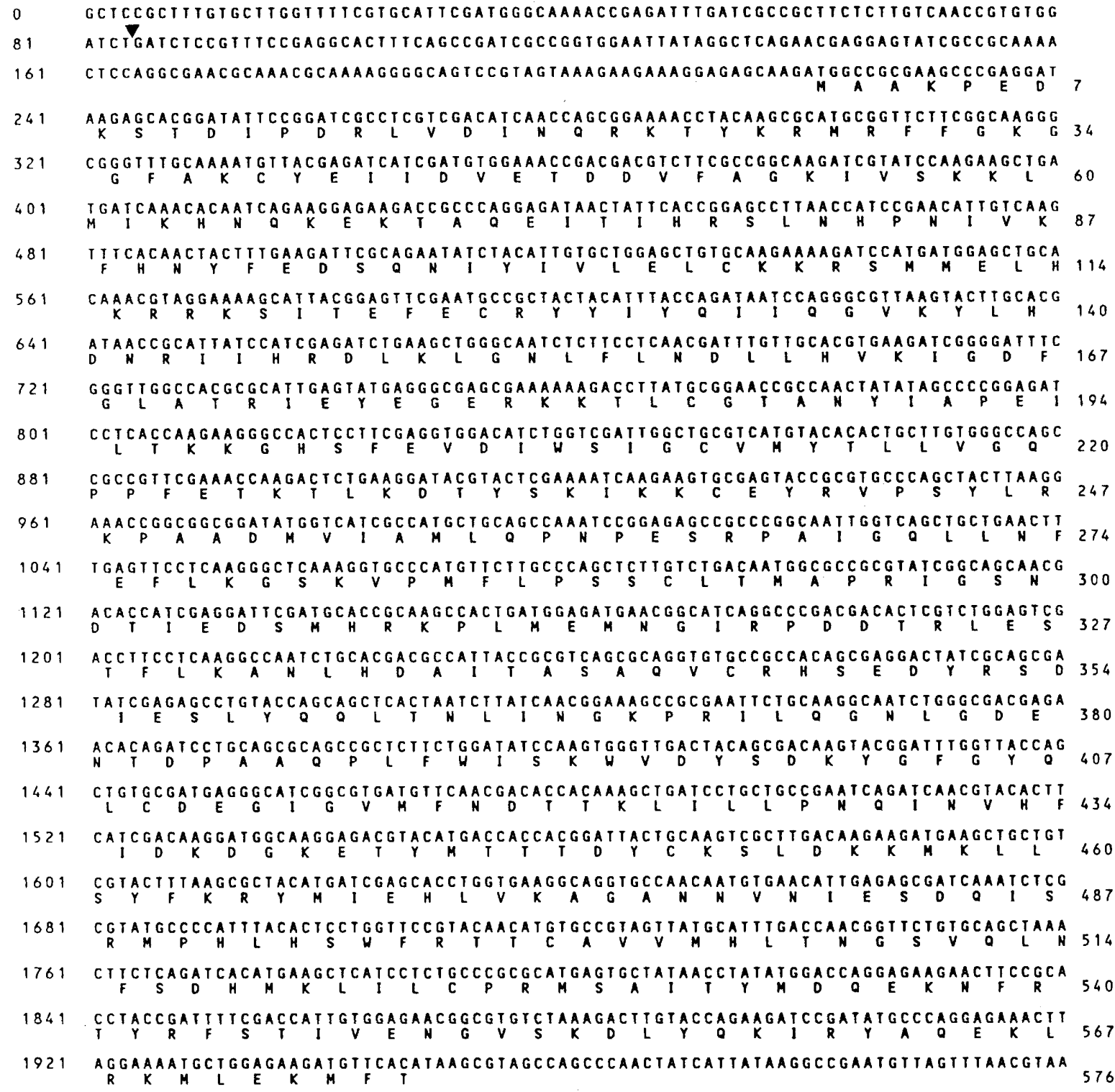

2001 ITCACGAATGCCCTGGCCAACTICATTTATAGCCCAGAAAGTATCCTCTCCCATCATCTTTTAAAATTGTAGTTCCCGTT

2081 CAAATTGATTTGTTCGATGTTTATAGAATTTATTTGTTTTTGCCCCTTCCCCTTCATATCGAAAATACTGCTTAAGTIAT

2161 ATICATCGICAGTGTTGGGCCTCCCTCAAAAGTAATTTAATATATCTGTTTAATGGTTTTCGTACACGATCCGATCACTT

2241 AATGCATTITAAAGAGATCAAATTAAATGTTIAAACTAAGCAAACGTGTTTCGAAATGCCTATATTCACCGAGGTGACTG

2321 ATAACAAAATTTTAATGCTGGATACATTATAAAAGTAATAGTGTAATATTGTGCGTTCGTAGTGCGCTATAGCGCCATTT

2401 AAAATAATACATAAGTTACAATACTGCTGCAAAGTGTTIAAGTGTACAAGTATATTCAACTTIGGCCAGAAATATCTGTA

2481 GCTATAGGATACAATTTGTAAATGCTTTTGAACTAAAAGCGAATATATATAAAATTTAAT

Figure 4. Nucleotide sequence of polo cDNAs. The sequence of the longer cDNA in the plasmid p9a2 is shown. The nucleotide sequence is enumerated at left; numbers at right refer to the amino acid sequence encoded by the longest open reading frame. The ends of the shorter cDNA sequence from $\mathrm{p} 2 \mathrm{a} 2$ are indicated by arrowheads. The polyadenylation signal AATATAT is found upstream of the $3^{\prime}$ ends of each transcript at nucleotides 2201 and 2523. As many protein kinases are themselves regulated by phosphorylation, we have searched for putative phosphorylation sites within the polo protein. We find potential sites for the following kinases (numbers refer to the last amino acid of the motif): (casein kinase I) 10; (casein kinase II) 113, 123, 357; (calmodulin kinase II) 245, 290, 328; (myosin heavy-chain kinase) 25, 58, 110, 202, 462, 500; (cAMP-dependent kinase) 120; (cGMP-dependent kinase) 489 (Kemp and Pearson 1990).

gene nim1 (Hanks et al. 1988). The fission yeast member of this family acts as an inducer of mitosis in the $c d c 2$ regulatory pathway. The $c d c 2$ gene itself encodes a 34-
$\mathrm{kD}$ protein kinase, $\mathrm{p} 34^{c d c 2}$ whose homolog is a component of mitosis promoting factor (MPF) in multicellular eukaryotes, and is thus part of a highly conserved mech- 
polo 22 KT YKRMRFF

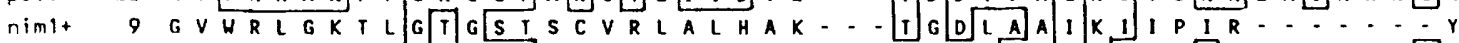

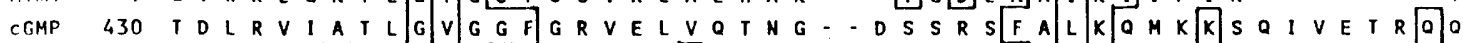

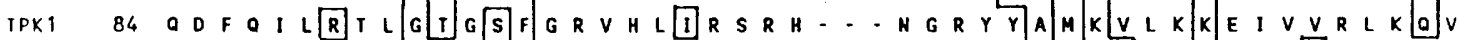

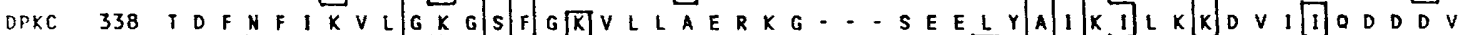

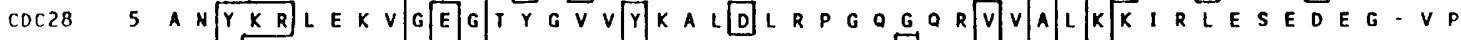

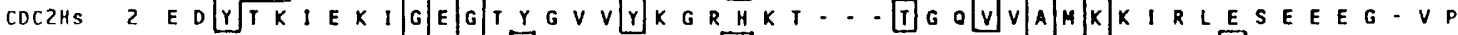

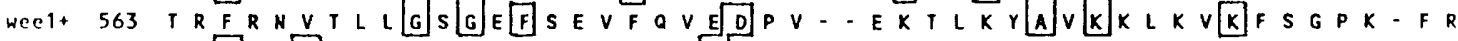

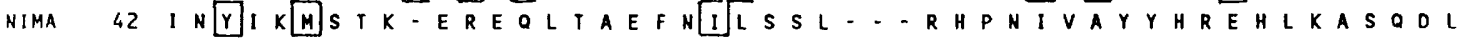

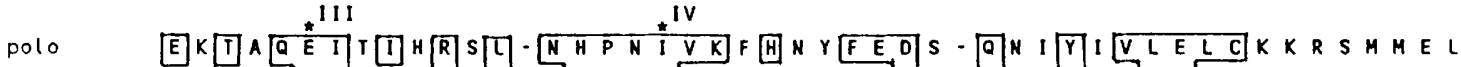

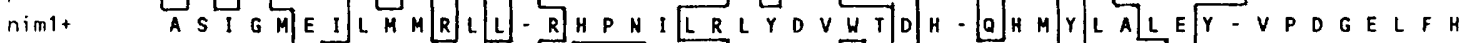
CGMP

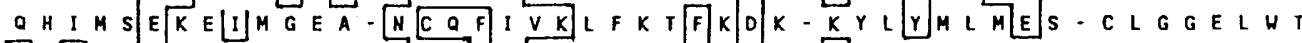

IPK 1

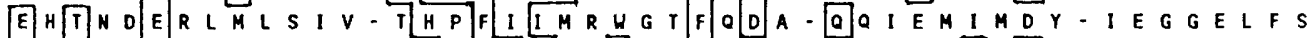

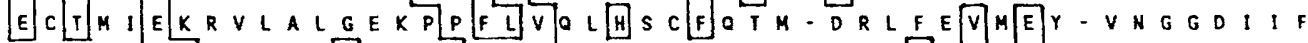

DPKC

$\operatorname{CDC} 28$

COC2HS

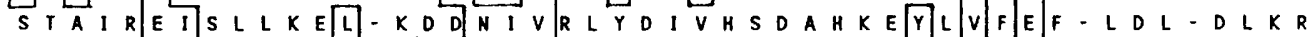
$S$ T A I R E I S L L K E L - R H P N I V S L O D V L M O D - S R L Y L I F E F - L S H - DLLKK

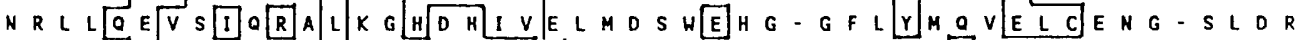
NIMA

polo

nim1

CGMP

TPK1

DPKC

$\operatorname{CDC} 28$

$\mathrm{COC2HS}$

Hee 1

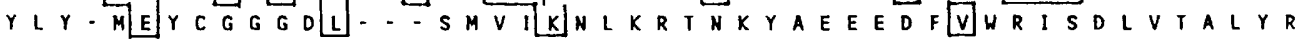

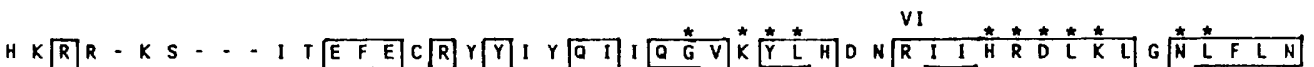
T 1 R K H G P - - L S E RE A A H Y L S Q I L D A V A A H C H R F R FR H R D L K K L E N T L L I K

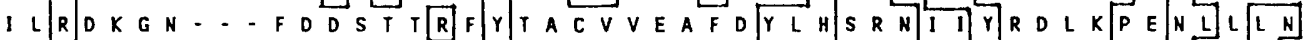

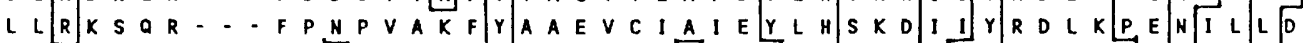
Q IOOFGK- - F K E P V A V F Y A A E T A A G L F F L H T K G i L V R D L K L D D h V L L D

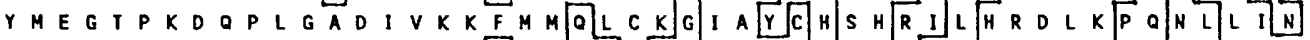
YLDS I P P G O Y M D S S I V K S Y I I O I L [

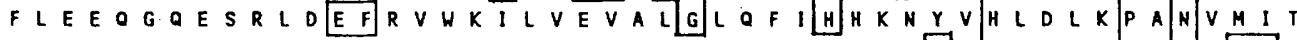

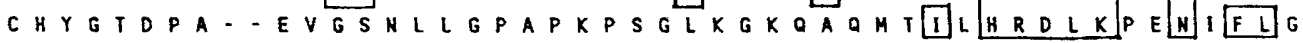

polo

nim1

CGMP

TPK1

DPKC

CDC28

CDC2HS

wee 1

NIMA

[DLL- HVKIGDFGLATRI E

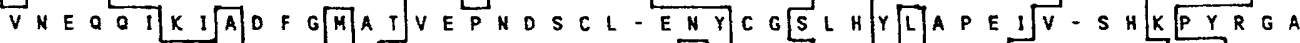
ER G Y GKLLVD D F G F A KKL O T GR K T - W TEF C G T P E Y V A P E V I - L N R G H D 1 -

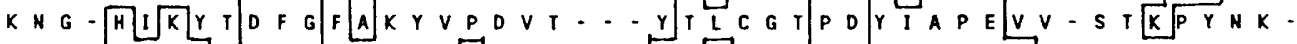

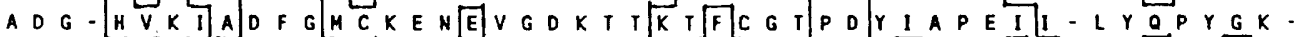

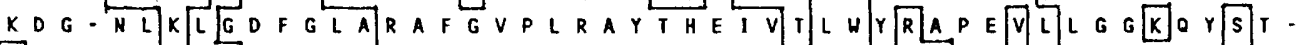
DKK G - T I $\quad K[L$ L

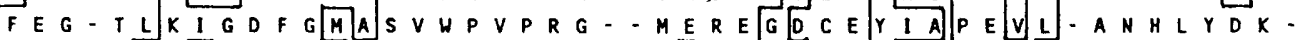
SDN - TVKLGOFGLSKLMHSHDFA - SDY DG TPFYMSEEIC-AAEKYTL -

polo

nim 1

CGMP

TPK1

DPKC

$\operatorname{CDC28}$

$\mathrm{COC} 2 \mathrm{HS}$

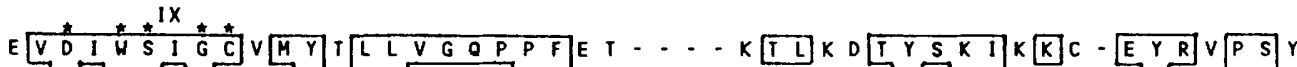

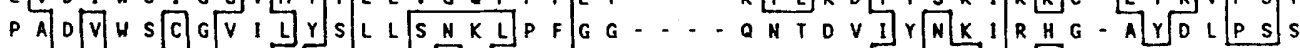

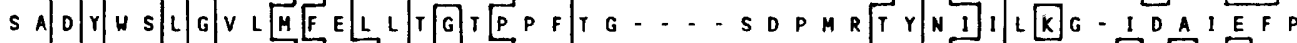

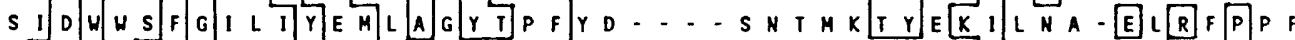

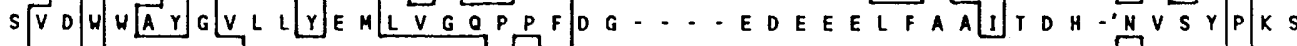

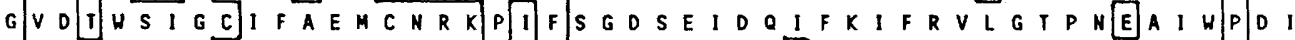

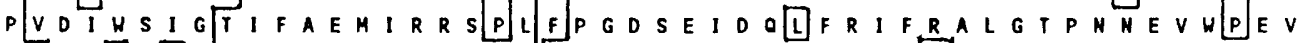

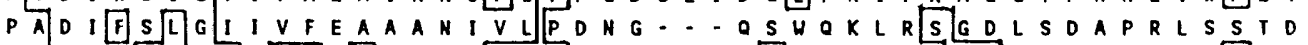

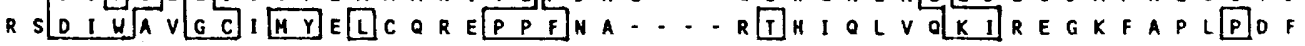

$X 1$
0

polo

nim1

CGMP

TPK 1

DPKC

$\operatorname{Coc} 28$

CDC2HS

Heel+

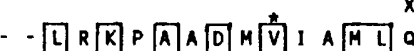

- is

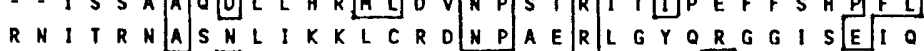
- FNEDVKDLLSRLIIIRDISORLG N L D N G TE D V K

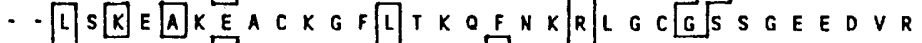
24/ L D P R G I D D L L D K L L L A Y D P I N N R I S A R R A A I H P Y F 24/L D D E N G L D L L S K H L I Y D P A K R I S G K M A L N H P Y F NIMA

18/ G O G G I D R V V F W M L S PEE P R N R P T D D O I L L A I D E V 277 $258(28.8)$ $683(26.6)$ $336(26.2)$ $594(26.2)$ $295(23.1)$ $288(22.7)$

$842(19.6)$

Figure 5. (See following page for legend.) 
A

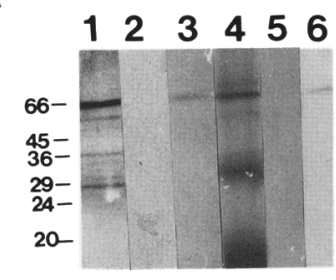

B

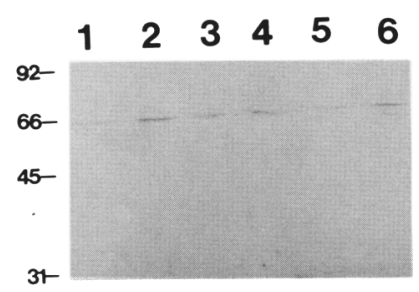

Figure 6. Detection of the putative polo kinase with antibodies. $(A)$ Coupled in vitro transcription and translation of polo cDNAs was carried out as described in Materials and methods. The total protein products of such a reaction with cDNAs $2 \mathrm{a} 2$ and $9 \mathrm{a} 2$ are shown in lanes 1 and 4 , respectively. The preimmune serum fails to precipitate any radiolabeled protein specified by either $2 \mathrm{a} 2$ (lane 2) or 9a2 (lane 5) cDNAs. The anti-polo rabbit serum $\mathrm{Rb} 287$ precipitates a single $65-\mathrm{kD}$ protein encoded by both $2 \mathrm{a} 2$ (lane 3) and 9a2 (lane 6). Molecular mass markers (in $\mathrm{kD})$ are shown at left. (B) Immunoblot of embryo extracts with the monoclonal anti-polo antibody MA75. Two loadings are shown of extracts from 2- to 4-hr embryos (lanes 1,2); 4- to 8-hr embryos (lanes 3,4); and 8- to 24-hr embryos (lanes 5,6). Molecular mass markers (in $\mathrm{kD}$ ) are shown at left.

anism that regulates the $G_{2}-M$ transition (for review, see Nurse 1990). The active form of $\mathrm{p} 34^{\text {cdc2 }}$ is associated with a mitotic cyclin, a protein that undergoes periodic degradation at each metaphase-anaphase transition in most mitotic cycles. The $\mathrm{p} 34^{c d c 2}$ kinase is activated by dephosphorylation on tyrosine and threonine residues in its ATP-binding site and phosphorylation on a threonine residue. The enzymes responsible for these phosphorylation or dephosphorylation steps have not been identified, although dephosphorylation at the tyrosine residue is controlled in fission yeast by $c d c 25$. Drosophila has a cdc25 homolog, string, that has been shown to positively regulate the $\mathrm{G}_{2}-\mathrm{M}$ transition within the mitotic domains of the cellularized embryo (Edgar and O'Farrell $1989,1990)$. p34 ${ }^{c d c 2}$ kinase is under the negative regulation of wee1, which itself encodes a protein kinase (Rus-
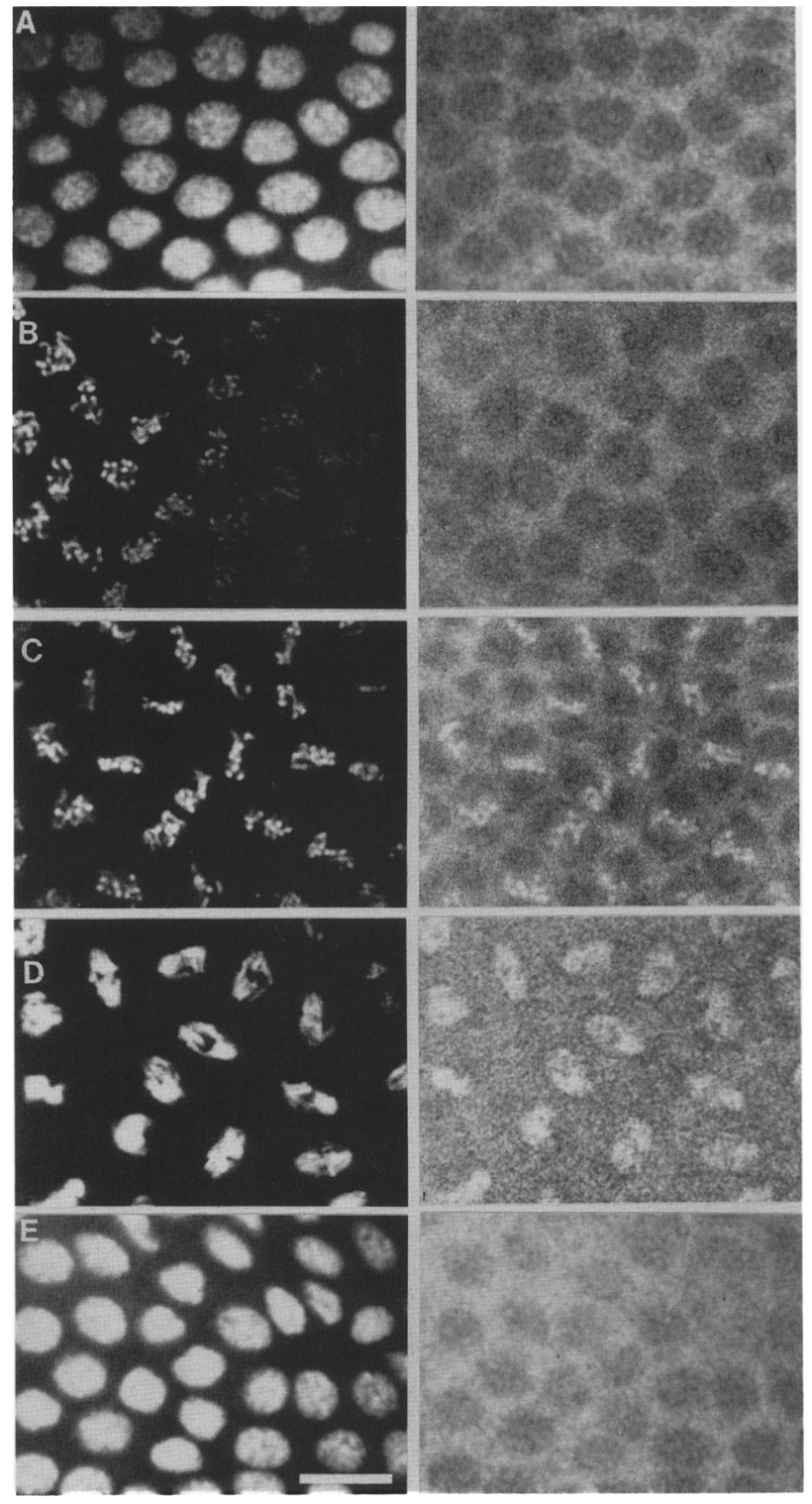

Figure 7. Cyclical distribution of polo kinase during syncytial mitotic cycles. Embryos were prepared to visualize DNA with propidium dioide (left), and the polo protein by indirect immunofluoresence (right) by using the techniques described previously by Whitfield et al. (1990) for confocal microscopy. The micrographs represent the following mitotic phases: $(A)$ interphase; $(B)$ prophase; $(C)$ metaphase; $(D)$ anaphase; $E$ ) late telophase. $E$ shows a gradient of telophase nuclei; those nuclei at top right are at earlier telophase stages.) Bar, $10 \mu \mathrm{m}$.

Figure 5. Comparison of the catalytic domain of the putative polo kinase with other kinases. The catalytic domains of polo and other kinases have been aligned with reference to the 11 sub-domains (I-XI) described by Hanks et al. (1988), indicating with asterisks (*) the most highly conserved residues noted by these investigators. These and all other conserved amino acids have been boxed. The kinases used for comparison are nim1 of Schizosaccharomyces pombe (Russell and Nurse 1987b); cGMP, cGMP-dependent protein kinase of Drosophila (Kalderon and Rubin 1989); TPK1, cAMP-dependent protein kinase of Saccharomyces cerevisiae (Toda et al. 1987; Lisziewicz et al. 1987); DPKC, protein kinase C-related gene product of Drosophila (Rosenthal et al. 1987); CDC28, cdc28 kinase of S. cerevisiae (Lorincz and Reed 1984); CDC2HS, functional homolog of S. pombe cdc2 from human (Lee and Nurse 1987); wee $1^{+}$, wee $1^{+}$kinase of $S$. pombe (Russell and Nurse 1987a); NIMA, never in mitosis gene of Aspergillus (Osmani et al. 1988). The number of the amino acid beginning the catalytic domain comparison is indicated on the first line of each sequence, and the amino acid final number is on the last line. Finally, percent identity is indicated in brackets. 

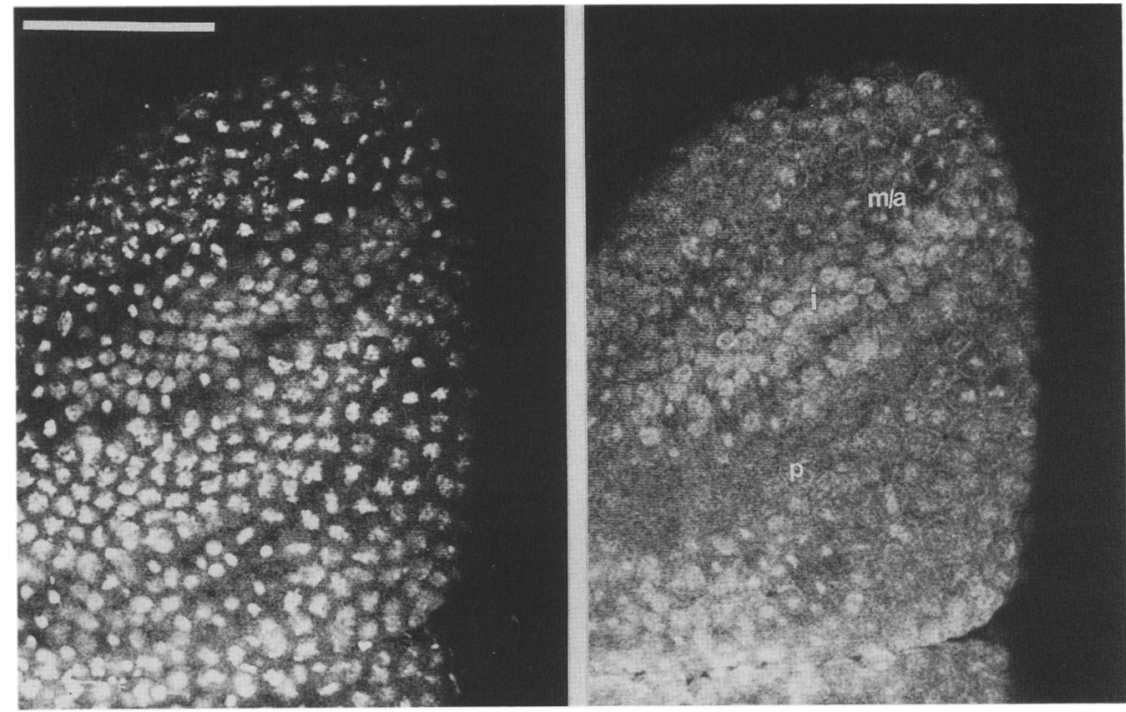

Figure 8. Distribution of polo kinase with respect to mitotic domains in cycle 14. Shown is the anterior of a cellularized embryo prepared for immunofluorescence as in Fig. 7. Several mitotic domains can be seen as distinct regions containing condensed chromatin. The three labeled areas exemplify cells at different cell cycle stages: $(\mathrm{m} / \mathrm{a})$ one of the mitotic domains with chromosomes in metaphase and anaphase showing staining with the antipolo antibody; (i) a region of interphase cells showing strong cytoplasmic antipolo staining; $(\mathrm{p})$ a region of prophase cells with diffuse anti-polo staining. Bar, 50 $\mu \mathrm{m}$. sell and Nurse 1987a; Featherstone and Russell 1991). Deletion of this fission yeast gene causes cells to enter mitosis at half the size of wild-type cells. The wee1kinase has been shown to catalyze its autophosphorylation on both tyrosine and serine residues (Featherstone and Russell 1991), and its coexpression with $c d c 2$ and cyclin in a baculoviral expression system suggests that it may phosphorylate the tyrosine residue that regulates p34 ${ }^{c d c 2}$ kinase activity (Parker et al. 1991). The nim1 protein kinase has been postulated, on the simplest interpretation of genetic interactions, to have its inducing effect upon mitosis by inhibiting wee $1^{+}$activity, although more complex interpretations are possible. Is the polo kinase the counterpart of nim 1 or just a family member? Until functional tests have been carried out, this remains an open question. polo kinase differs from the nim1 kinase by having a longer carboxy-terminal domain. Furthermore, its catalytic domain shows only $29 \%$ identity to that of nim 1 . This compares to a $59 \%$ identity between fission yeast $c d c 2$ and its functional Drosophila counterpart. On the other hand, string, the functional counterpart of $c d c 25$ (Edgar and O'Farrell 1989; Jimenez et al. 1990), shows just 35\% identity to the fission yeast gene but only in a carboxy-terminal domain corresponding to $\sim 39 \%$ of its length.

The activation of $c d c 2$ kinase is part of a cascade of phosphorylation events required for the transit of the cell into and through mitosis. Other putative protein kinases have been described that are essential for these events, but their precise role is uncertain. The $\operatorname{nim} A$ gene of Aspergillus, for example, appears to have analogous functions to $c d c 2$ of fission yeast and may represent another component of this regulatory pathway. Recessive mutations in nimA result in a cell-cycle block late in $\mathrm{G}_{2}$ (Morris 1976; Oakley and Morris 1983; Osmani et al. 1987), whereas inducible overexpression of the gene causes mitotic induction in which chromatin is maintained in a condensed state (Osmani et al. 1988). It is clear from its sequence that the $\operatorname{nim} A$ kinase is homologous to neither of the kinases encoded by $c d c 2$, wee1, or nim 1 of fission yeast nor the polo kinase. Another protein kinase has been identified in mammalian cells that may act to maintain the mitotic state since when it is overexpressed in $\mathrm{CHO}$ cells, it appears to result in a delay in the progression through telophase and in the subsequent entry into S (Bunnell et al. 1990). Many of the rounded-up cells that result from overexpression of this kinase contain tubulin mid-bodies similar to those seen in the telophase spindle. Not only is a complex network of protein phosphorylation and dephosphorylation involved in regulating the entry into mitosis, but there is also a major requirement for protein phosphorylation in the mitotic events of nuclear membrane breakdown (e.g., Gerace and Blobel 1980), chromosome condensation (e.g., Bradbury et al. 1974), spindle formation, and the activation of microtubule-organizing centers (Piras and Piras 1975; Vandre et al. 1984; Verde et al. 1990). Although some of these phosphorylation events have been postulated to be mediated directly by p34 ${ }^{c d c 2}$ kinase (Peter et al. 1990; Ward and Kirschner 1990), the phosphorylation of such a diverse set of substrates may well require a number of protein kinases.

Do the phenotypes resulting from mutation in polo give any clues to its point of action? This question is difficult to address with the existing alleles because polo mutants, in common with other Drosophila mitotic mutants, have been selected for their developmental phenotype. These mutations are therefore unlike the cell-cycle mutations in the yeasts and in Aspergillus that have been selected on the basis of a conditional lethal phenotype, usually temperature sensitivity, and in which it is possible to follow the effect of mutation in all cells following a temperature shift. The embryos of females homozygous for polo ${ }^{1}$ fail to develop, as a consequence of totally aberrant mitotic events throughout the syncytial stages (Sunkel and Glover 1988). However, chromatin, 
which is highly disorganized, does appear to undergo condensation and decondensation, and DNA replication continues to produce many polyploid nuclei. Such a phenotype appears to be a common feature of many maternal-effect mutations that affect mitosis in the syncytial embryo. In such cases when one disrupts the nuclear cycle, centrosomes may break free from nuclei and undergo autonomous replication reflecting the loose coupling of the nuclear and cytoplasmic events of mitosis at this developmental stage. Thus, free centrosomes are seen in embryos of females homozygous for $g n u$, in which nuclear division is prevented leading to giant nuclei (Freeman et al. 1986); abnormal spindle (Gonzalez et al. 1990); lodestar, which leads to lagging anaphase chromosomes (Girdham and Glover 1991); aurora, which leads to spindle branching and polyploidy $(M$. Leibowitz and D.M. Glover, in prep.); $f_{s}(1) y$ (Lin and Wolfner 1991), in which there are few if any early nuclear divisions; and $a b c$ (Vessey et al. 1991). Centrosomes will also dissociate from nuclei and replicate autonomously following the injection of aphidicolin to inhibit DNA replication (Raff and Glover 1988). However, not only can free centrosomes not be seen in polo embryos but the disorganized chromatin is associated with highly branched microtubules that do not appear to be nucleated by organized centrosomes. Although the $\mathrm{Bx} 63$ centrosomal antigen is present within these embryos, it only aggregates into punctate bodies visible by immunofluorescence later in the aberrant development of these embryos. These bodies are associated with the polyploid nuclei (Sunkel and Glover 1988). The lack of centrosomes in polo embryos is therefore unusual among the maternal-effect mitotic mutations that have been described to date and may point toward the polo kinase having a role in regulating both nuclear and cytoplasmic aspects of the mitotic cycle.

We also see an effect of the polo ${ }^{1}$ mutation on the mitotic apparatus in larval neuroblasts. Previously, we had observed a high frequency of polyploid cells in orcein-stained squashed preparations of larval neuroblasts. Many of these appeared to be in a circular arrangement leading us to speculate that they might be associated with a single spindle pole (Sunkel and Glover 1988). In this paper we present evidence for such monopolar structures within polo brains. The mitotic phenotypes of the recessive polo ${ }^{1}$ mutation are seen in homozygous mutant larvae as the maternal wild-type protein is gradually eliminated and replaced by mutant protein. Sufficient cells survive the effects of the mutation such that adults are produced. This points to the protein produced by the polo $^{1}$ allele as having some residual function because maternal protein in larvae homozygous for the polo ${ }^{2}$ allele, disrupted by a P-element insertion, only enables their survival to second instar, a point at which we have been unable to examine the mitotic phenotype. Our recent observations on larval neuroblasts in third-instar larvae homozygous for polo indicate a broad pattern of mitotic defects. Not only does the mutation affect the organization of spindle poles but it also results in polyploidy and in cells in which aspects of the mitotic cycle are delayed, often leading to overcondensation of chromosomes. In this respect, the effects of polo ${ }^{1}$ differ from the effects of drugs such as colchicine, or mutations such as asp, which arrest the mitotic cycle of neuroblasts at clearly defined points (Gonzalez et al. 1990; Whitfield et al. 1990). The pleiotropy of the polo mutation is much more similar to that of the null allele of the protein phosphatase 1 locus at 87B (Axton et al. 1990). Such pleiotropic effects may indicate either that these enzymes act upon a wide range of substrates or that they act in the upper echelons of the mitotic regulatory hierarchy. We are now in a position to begin to ask questions relating to the substrate specificity of the polo kinase and also to study its interaction with the growing collection of mitotic mutants of Drosophila to study its role in mitotic regulation.

\section{Materials and methods}

Molecular genetics of polo

The polo ${ }^{2}$ allele was identified in a collection of larval and pupal lethal mutations induced by crossing females homozygous for a third chromosome marked with red $e$ with P males. Stocks were established from single-pair matings of the grandsons of the dysgenic cross with females carrying balancer chromosomes. The mutant third chromosomes from these stocks were tested for their ability to complement the polo ${ }^{1}$ allele (Sunkel and Glover 1988). Several isogenic lines were established from the original stock, K3.1, that carries polo ${ }^{2}$. In situ hybridization of a P-element probe to polytene chromosomes showed that the third chromosome carried six $\mathrm{P}$ transposons. Recombinant chromosomes were then generated between the P-element-carrying chromosome and a multiply marked chromosome carrying the recessive alleles $r u h$ th st cu sr ca. Recombinant chromosomes in the $s t-c u$ interval, in which polo had been reported to map, were tested for polo ${ }^{2}$. Recombinants showing the polo phenotype were found by in situ hybridization to have a $\mathrm{P}$ element at $77 \mathrm{~A}$, whereas all polo ${ }^{+}$recombinants lacked this $\mathrm{P}$ element. This experiment also revealed two unrelated lethal mutations in the th-cu interval on the K3.1 chromosome. As one of these lethal mutations $\left(I^{2}\right)$ was still present on the recombinant chromosome recl, a second round of recombination was undertaken with a chromosome marked with $r u h$ th. Unfortunately, recombinants in the th-cu interval that carried polo ${ }^{2}$ also carried $l^{2}$. One such recombinant chromosome / $\mathrm{rec} 2$ : ru h th lethal polo cu sr cal was therefore subjected to further recombination with a chromosome marked with st in ri eag Ki. st polo cu sr ca recombinants were collected that had lost the flanking lethal mutation in the recombination process but still carried the $\mathrm{P}$ element inserted in $77 \mathrm{~A}$ as revealed by in situ hybridization. We refer to this chromosome as rec3.

To confirm that the $\mathrm{P}$ element inserted at $77 \mathrm{~A} 3$ was responsible for the polo phenotype in polo ${ }^{2}$, the rec 2 chromosome was subjected to hybrid dysgenesis to select for revertants of the polo $\mathrm{o}^{2}$ mutation. Males of a line carrying rec2/TM6 were crossed to TM1/TM3 M females. Four fully viable and fertile polo revertants were studied in a total of 11,359 chromosomes screened. In situ hybridizations showed that all had lost the P element at $77 \mathrm{~A} 3$ while maintaining various combinations of other P elements present on the chromosome. Southern blotting analysis indicated that a 6-kb EcoRI fragment present on the rec 2 chromosome was no longer present but was replaced by a fragment that was $1.6 \mathrm{~kb}$ shorter (not shown). 


\section{Molecular cloning of polo}

DNA was extracted from flies carrying the rec3 chromosome balanced over TM3, partially digested with Sau3A, and used to construct a genomic library in $\lambda E M B L 4$. Recombinants carrying $P$ elements and their flanking genomic sequences were selected by hybridization with an 0.8 - $\mathrm{kb}$ fragment from the 25.1 plasmid (O'Hare and Rubin 1983). Nineteen positives were isolated, which fell into two classes by the criteria of their restriction cleavage maps and by in situ hybridization to sites $82 \mathrm{C}$ and 77A3 on wild-type polytene chromosomes. DNAs prepared from the class of phage hybridizing to 77A3 were used to probe libraries of genomic DNA from the wild-type strain Canton-S in EMBL4 and in $\lambda$-Dash.

\section{P-element-mediated germ-line transformation}

Transformations were carried out as described by Axton et al. (1990). The 10-kb BamHI fragment from phage E-1 (Fig. 2) was introduced into pW8 (Klemenz et al. 1987) and injected together with the helper element, pUChs 2-3, into embryos homozygous for $w^{118}$. Lines were established in which the insertions were carried on either the $\mathrm{X}$ or second chromosomes. $w^{118} \mathrm{P}[w$ pol $]$ males from lines carrying $\mathrm{X}$ insertions were crossed to virgin $w^{118}$; ru st $\mathrm{pol}^{1}$ e ca/TM3 females. Individuals carrying the transposon were selected by their white ${ }^{+}$phenotype, and the chromosome carrying $\mathrm{pol}^{1}$ was identified by its segregation from TM3. Flies of the genotype $w^{118} \mathrm{P}[\mathrm{w}$ pol $]$ ru st pol $1^{1} e \mathrm{ca}$ were backcrossed against $w^{118}$; ru st pol ${ }^{1}$ e ca/TM3 females and female offspring of the genotype $w^{118} \mathrm{P}[w \mathrm{pol}] / \mathrm{w}^{118}$; ru st pol $e$ ca/ru st pol e ca were selected and checked for fertility. All were found to be fertile, giving rise to embryos that developed to produce adults. An analogous procedure was followed by using the polo ${ }^{2}$ allele, in which case both lethality and fertility were fully complemented.

\section{Generation of antibodies}

Generation of antibodies, Western blotting, and the fixing and immunostaining of embryos were all carried out as described previously (Whitfield et al. 1990). A SalI fragment of the cDNA clone p9a2 encoding the amino-terminal part of the protein (Fig. 2) was subcloned into the expression vector pUR292 (Ruther and Muller-Hill 1983) to give the plasmid pUR9a2N in which it is expressed as a fusion protein with Escherichia coli $\beta$-galactosidase. A SphI-NotI fragment was also subcloned into the pAR expression vector (Studier and Moffatt 1986). This construct encodes a fusion protein in which the 28 amino-terminal amino acids of polo are replaced with 11 amino acids from the amino terminus of the T7 S10 protein. Protein preparations from bacterial cultures expressing these fusion proteins were fractionated by preparative SDS-PAGE. The protein specified by pUR9a2N was injected into a rabbit that produced a serum designated RB287. The protein specified by pAR9a2F was injected into mice that were used to raise several monoclonal antibodies as described in Harlow and Lane (1988). Polyclonal sera were absorbed against $E$. coli extracts enriched in $\beta$-galactosidase to remove antibodies against this component of the fusion protein. Immunostaining of embryos was performed with the polyclonal antiserum Rb287 and mAbs MA75 and MA81, all of which gave identical staining patterns.

\section{In vitro transcription, translation, and immunoprecipitation}

In vitro transcription was performed by using an SP6 transcription kit from Amersham. Two micrograms of either p2a 2 or p9a2 cDNA was linearized with NboI and incubated with 10 units of SP6 polymerase and 0.025 units of RNase inhibitor in the recommended buffer at $37^{\circ} \mathrm{C}$ for $1 \mathrm{hr}$. Plasmid DNA was digested with RNase-free DNase and the RNA isolated by phenol-chloroform extraction followed by precipitation in $5 \mathrm{M}$ ammonium acetate. In vitro translation was performed on $200 \mathrm{ng}$ of RNA incubated with $17.5 \mu \mathrm{Ci}$ of $\left[{ }^{35} \mathrm{~S}\right]$ methionine $(800-1200$ $\mathrm{Ci} / \mathrm{mmole}$, Amersham) in $20 \mu \mathrm{l}$ of rabbit reticulocyte lysate (Amersham) for $1 \mathrm{hr}$ at $37^{\circ} \mathrm{C}$. Before boiling for $3 \mathrm{~min}, 6.5 \mu \mathrm{l}$ of the reaction was prepared for SDS-PAGE by incubation with an equal volume of RNase $(100 \mu \mathrm{g} / \mathrm{ml}$ in $50 \mathrm{~mm}$ EDTA) for $15 \mathrm{~min}$ at $37^{\circ} \mathrm{C}$, followed by the addition of a further volume of SDSgel-loading buffer. Immunoprecipitation was carried out by diluting the remaining $20 \mu \mathrm{l}$ to $1 \mathrm{ml}$ in NET [50 mM Tris (pH 7.5), $150 \mathrm{mM} \mathrm{NaCl}, 0.1 \% \mathrm{NP}-40,1 \mathrm{~mm}$ EDTA, $0.25 \%$ gelatin, $0.02 \%$ sodium azidel containing $1 \mathrm{mM}$ PMSF. This was divided into two microcentrifuge tubes for centrifugation for $15 \mathrm{~min}$ at $4^{\circ} \mathrm{C}$ in a microcentrifuge. Either preimmune or $\operatorname{Rb} 287$ serum $(5 \mu l)$ was added, and the mixture was incubated for $15 \mathrm{~min}$ at $4^{\circ} \mathrm{C}$. IgGsorb $(500 \mathrm{ng})$ was added, and the incubation continued for an additional $15 \mathrm{~min}$ at $4^{\circ} \mathrm{C}$. Immunoprecipitates were collected by centrifugation and washed several times before being resuspended in $10 \mu \mathrm{l}$ of SDS-gel-loading buffer. Following electrophoresis, the gel was fixed in methanol, and dried for autoradiography.

\section{Acknowledgments}

We thank the Cancer Resarch Campaign of Great Britain and the Instituto de Investigacao Cientifica and the Junta Nacional de Investigaçâo Cientifica e Tecnologica (grant 67/676) of Portugal for supporting this work. We also thank Jordan Raff for carrying out some of the initial in situ hybridization experiments to localize polo transcripts in embryos and Ines Chavez for the screening of polo revertants. We thank Kevin O'Hare and Andrew Tomlinson for providing useful bits of $P$ elements.

The publication costs of this article were defrayed in part by payment of page charges. This article must therefore be hereby marked "advertisement" in accordance with 18 USC section 1734 solely to indicate this fact.

\section{References}

Axton, J.M., V. Dombradi, P.T.W. Cohen, and D.M. Glover. 1990. One of the protein phosphatase 1 isoenzymes in Drosophila is essential for mitosis, Cell 63: 33-46.

Bradbury, E.M., R.J. Inglis, and H.R. Matthews. 1974. Control of cell division by very rich lysine (F1) phosphorylation. Nature 247: 257-261.

Brown, N.H. and F.C. Kafatos. 1988. Functional cDNA libraries from Drosophila embryos. J. Mol. Biol. 203: 425-437.

Bunnel, B.A., L.S. Heath, D.E. Adams, J.M. Lahti, and V.J. Kidd. 1990. Increased expression of a $58 \mathrm{kD}$ protein kinase that leads to changes in the CHO cell cycle. Proc. Natl. Acad. Sci. 87: 7467-7471.

Edgar, B.A. and P.H. O'Farrell. 1989. Genetic control of cell division patterns in the Drosophila embryo. Cell 57: 177187.

1990. The three postblastoderm cell cycles of Drosophila embryogenesis are regulated in G2 by string. Cell 62: 469-480.

Featherstone, C. and P. Russell. 1991. Fission yeast p107 ${ }^{\text {weel }}$ mitotic inhibitor is a tyrosine/serine kinase. Nature 349: 808-811. 
Foe, V.E. 1989. Mitotic domains reveal early commitment of cells in Drosophila embryos. Development 107: 1-22.

Foe, V. and B.M. Alberts. 1983. Studies of nuclear and cytoplasmic behaviour during the five mitotic cycles that precede gastrulation in Drosophila embryogenesis. J. Cell Sci. 61: 31-70.

Frasch, M., D.M. Glover, and H. Saumweber. 1985. Nuclear antigens follow different pathways into daughter nuclei during mitosis in Drosophila embryos. J. Cell. Sci. 82: 115-172.

Freeman, M. and D.M. Glover. 1987. The gnu mutation of Drosophila causes inappropriate DNA synthesis in unfertilized and fertilized eggs. Genes \& Dev. 1: 924-930.

Freeman, M., C. Nüsslein-Volhard, and D.M. Glover. 1986. The dissociation of nuclear and centrosomal division in gnu, a mutation causing giant nuclei in Drosophila. Cell 46: 457468.

Gatti, M. and B.S. Baker. 1989. Genes controlling essential cell cycle functions in Drosophila melanogaster Genes \& Dev. 3: 438-453.

Gatti, M., D.A. Smith, and B.S. Baker. 1983. A gene controlling the condensation of heterochromatin in Drosophila melanogaster. Science 221: 83-85.

Gerace, L. and G. Blobel. 1980. The nuclear envelope lamina is reversibly polymerized during mitosis. Cell 19: 277-287.

Girdham, C.H. and D.M. Glover. 1991. Chromosome tangling and breakage at anaphase result from mutations in lodestar, a Drosophila gene encoding a putative nucleoside triphosphate-binding protein. Gene \& Dev., 5: 1786-1799.

Gonzalez, C., R.D.C. Saunders, J. Casal, I. Molina, M. Carmena, P. Ripoll, and D.M. Glover. 1990. Mutations at the asp locus lead to multiple free centrosomes in syncytial embryos, but restrict centrosome duplication in larval neuroblasts. $J$. Cell Sci. 96: 605-616.

Hanks, S.K., A.M. Quinn, and T. Hunter. 1988. The protein kinase family: Conserved features and deduced phylogeny of the catalytic domains. Science 241: 42-52.

Harlow, E. and D. Lane. 1988. Antibodies: A laboratory manual. Cold Spring Harbor Laboratory, Cold Spring Harbor, New York.

Jimenez, J., L. Alphey, P. Nurse, and D.M. Glover. 1990. Complementation of fission yeast $\operatorname{cdc} 2^{\text {ts }}$ and $\operatorname{cdc} 25^{\text {ts }}$ mutants identifies two cell cycle genes from Drosophila, a cdc2 homologue and string. EMBO I. 9: 3565-3571.

Kalderon, D. and G. Rubin. 1989. cGMP dependent protein kinase genes in Drosophila. J. Biol. Chem. 264: 10738-10748.

Klemenz, R., U. Weber, and W. Gehring. 1987. The white gene as a marker in a P-element vector for gene transformation in Drosophila. Nucleic Acids Res. 15: 3947-3959.

Lee, M.G. and P. Nurse. 1987. Complementation used to clone a human homologue of the fission yeast cell cycle control gene cdc2. Nature 327: 31-35.

Lehner, C.F. and P.H. O'Farrell. 1989. Expression and function of Drosophila cyclin A during embryonic cell cycle progression. Cell 56: 957-968.

1990. The roles of cyclins A and B in mitotic control. Cell 61: 535-547.

1990b. Drosophila cdc2 homologues: A functional homologue is coexpressed with a cognate varient. EMBO $J$. 9: 3573-3581.

Lin, H. and M.F. Wolfner. 1991. The Drosophila maternal effect gene $\mathrm{fs}(1) \mathrm{Ya}$ encodes a cell cycle dependent nuclear envelope component required for embryonic mitoses. Cell 64: 49-62.

Lisziewicz, J.A., H. Godany, H. Forster, and H. Kuntzel. 1987. Isolation and nucleotide sequence of a Saccharomyces cerevisiae protein kinase gene suppressing the cell cycle start mutation cdc25. J. Biol. Chem. 262: 2549-2553.
Lorincz, A.T. and S.I. Reed. 1984. Primary structure homology between the product of yeast cell division gene CDC28 and vertebrate oncogenes. Nature 307: 183-185.

Morris, N.R. 1976. Mitotic mutants of Aspergillus nidulans Genet. Res. 26: 237-254.

Nurse, P. 1990. Universal control mechanism regulating onset of M-phase. Nature 344: 503-507.

Oakley, B.R. and N.R. Morris. 1983. A mutation in Aspergillus that blocks the transition from interphase to prophase. $/$. Cell. Biol. 96: 1155-1158.

O'Hare, K. and G. Rubin. 1983. Structures of transposable elements and their sites of insertion and excision in the Drosophila melanogaster genome. Cell 34: 25-35.

Osmani, S.A., G.S. May, and N.R. Morris. 1987. Regulation of the mRNA levels of nimA, a gene required for the G2-M transition in Aspergillus nidulans. I. Cell. Biol. 104: 14951504.

Osmani, S.A., R.T. Pu, and N.R. Morris. 1988. Mitotic induction and maintenance by overexpression of a G2 specific gene that encodes a potential protein kinase. Cell 53: 237244.

Parker, L.L., S. Atherton-Fessler, M.S. Lee, S. Ogg, J.L. Falk, K.I. Swenson, and H. Piwnica-Worms. 1991. Cyclin promotes the tyrosine phosphorylation of $\mathrm{p} 34^{\mathrm{cdc} 2}$ in a wee $1^{+}$dependent manner. $E M B O$ J. 10: 1255-1263.

Peter, M., J. Nakagawa, M. Doree, J.C. Labbe, and E.A. Nigg. 1990. In vitro disassembly of the nuclear lamina and M-phase specific phosphorylation of lamins by cdc2 kinase. Cell 61: 591-692.

Piras, R. and M.M. Piras. 1975. Changes in microtubule phosphorylation during cell cycle of HeLa cells. Proc. Natl. Acad. Sci. 72: 1161-1165.

Raff, J.W. and D.M. Glover. 1988. Nuclear and cytoplasmic mitotic cycles continue in Drosophila embryos in which DNA synthesis is inhibited with aphidicolin. J. Cell Biol. 107: 2009-2019.

Raff, J., W.G.F. Whitfield, and D.M. Glover. 1990. Two distinct mechanisms localise cyclin B transcripts in syncytial Drosophila embryos. Development 110: 1249-1261.

Rosenthal, A., L. Rhee, R. Yadegani, R. Paro, A. Ullrich, and D.V. Goeddel. 1987. Structure and sequence of a Drosophila melanogaster protein kinase C gene. EMBO J. 6: 433-441.

Russell, P. and P. Nurse. 1987a. Negative regulation of mitosis by wee $1^{+}$, a gene encoding a protein kinase homolog. Cell 49: $599-567$.

. 1987b. The mitotic inducer niml ${ }^{+}$functions in a regulatory network of protein kinase homologs controlling the initiation of mitosis. Cell 49: 5689-5696.

Rüther, U. and B. Müller-Hill. 1983. Early identification of cDNA clones. EMBO J. 2: 1791-1794.

Studier, F.W. and B.A. Moffatt. 1986. Use of bacteriophage T7 RNA polymerase to direct selective high level expression of cloned genes. J. Mol. Biol. 189: 113-130.

Sunkel, C.E. and D.M. Glover. 1988. polo, a mitotic mutant of Drosophila displaying abnormal spindle poles. I. Cell. Sci. 89: 25-38

Szabad, J. and P.J. Bryant. 1982. The mode of action of discless mutations in Drosophila melanogaster. Dev. Biol. 93: 240256.

Tautz, D. and C. Pfeifle. 1989. A non radioactive in situ hybridisation method for the localisation of specific RNAs in Drosophila embryos reveals translational control of the segmentation gene hunchback. Chromosoma 98: 81-85.

Toda, T., S. Cameron, P. Sass, M. Zoller, and M. Wigler. 1987. Three different genes in S. cerevisiae encode the catalytic subunits of the cAMP-dependent protein kinase. Cell 
50: $277-287$.

Truman, J.W. and M. Bate. 1988. Spatial and temporal patterns of neurogenesis in the central nervous system of Drosophila melanogaster. Dev. Biol. 125: 145-157.

Underwood, E.M., A.S. Briot, K.Z. Doll, R.L. Ludwiczak, D.C. Otteson, J. Tower, K.B. Vessey, and K. Yu. 1990. Genetics of 51D-52A, a region containing several maternal-effect genes and 2 maternal-specific transcripts in Drosophila. Genetics 126: 639-650.

Vandre, D.D., F.M. Davis, P.N. Rao, and G.G. Borisy. 1984. Phosphoproteins are components of mitotic microtubule organising centers. Proc. Natl. Acad. Sci. 81: 4439-4443.

Verde, F., J.C. Labbe, M. Doree, and E. Karsenti. 1990. Regulation of microtubule dynamics by cdc2 protein kinase in cellfree extracts of Xenopus eggs. Nature 343: 233-238.

Vessey, K.B., R.L. Ludawiczak, A.S. Briot, and E.M. Underwood. 1991. abnormal chromatin, a maternal effect locus in Drosophila melanogaster. I. Cell. Sci. 98: 233-243.

Ward, G.E. and M.W. Kirschner. 1990. Idenification of cell cycle-regulated phosphorylation sites on nuclear lamin C. Cell 61: 561-577.

Whitfield, W.G.F., S.E. Millar, H. Saumweber, M. Frasch, and D.M. Glover. 1988. Cloning of a gene encoding an antigen associated with the centrosome in Drosophila. I. Cell. Sci. 89: $467-480$.

Whitfield, W.G.F., C. Gonzalez, E. Sanchez-Herrera, and D.M. Glover. 1989. Transcripts of one of two Drosophila cyclin genes become localised in pole cells during embryogenesis. Nature 338: 337-340.

Whitfield, W.G.F., C. Gonzalez, G. Maldonado-Codina, and D.M. Glover. 1990. The A- and B-type cyclins of Drosophila are accumulated and destroyed in temporally distinct events that define separate phases of the G2-M transition. EMBO J. 9: 2563-2572.

Zalokar, M. and I. Erk. 1976. Division and migration of nuclei during early embryogenesis of Drosophila melanogaster. $J$. Microbiol. Cell 25: 97-106. 


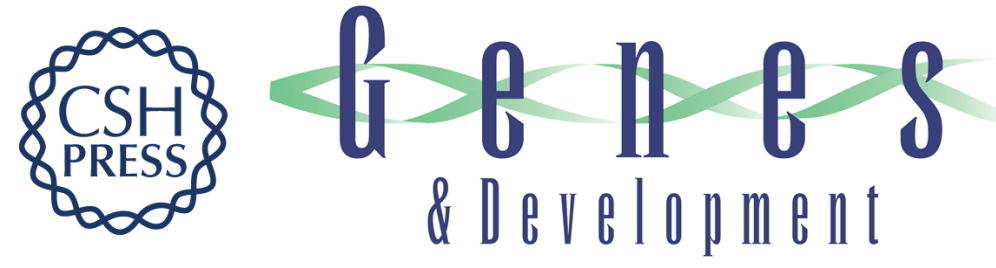

\section{polo encodes a protein kinase homolog required for mitosis in Drosophila.}

S Llamazares, A Moreira, A Tavares, et al.

Genes Dev. 1991, 5:

Access the most recent version at doi:10.1101/gad.5.12a.2153

References This article cites 58 articles, 20 of which can be accessed free at:

http://genesdev.cshlp.org/content/5/12a/2153.full.html\#ref-list-1

License

Email Alerting

Service

Receive free email alerts when new articles cite this article - sign up in the box at the top right corner of the article or click here.

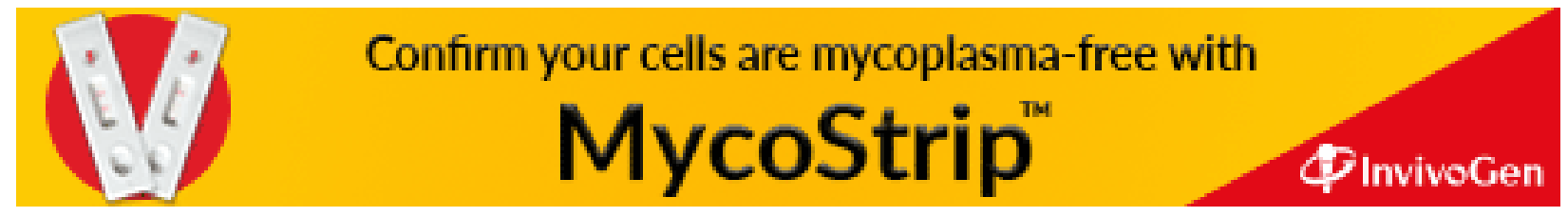

